\title{
Alveolar-capillary reserve during exercise in patients with chronic obstructive pulmonary disease
}

Mehrdad Behnial

Courtney MWheatley ${ }^{2}$

Alberto Avolio 3

Bruce D Johnson ${ }^{2}$

'Division of Critical Care, Florida Hospital, Orlando, FL, ${ }^{2}$ Division of Cardiovascular Diseases, Mayo Clinic, Scottsdale, AZ, USA; ${ }^{3}$ Australian School of Advanced Medicine, Faculty of Medicine and Health Sciences, Macquarie University, Sydney, NSW, Australia
Correspondence: Mehrdad Behnia

Division of Critical Care, Florida

Hospital, 60I E Rollins Street,

Orlando, FL 32803, USA

$\mathrm{Tel}+\mathrm{I} 7063398634$

Email doctorbehnia@gmail.com
This article was published in the following Dove Press journal:

International Journal of COPD

24 October 2017

Number of times this article has been viewed

Background: Factors limiting exercise in patients with COPD are complex. With evidence for accelerated pulmonary vascular aging, destruction of alveolar-capillary bed, and hypoxic pulmonary vasoconstriction, the ability to functionally expand surface area during exercise may become a primary limitation.

Purpose: To quantify measures of alveolar-capillary recruitment during exercise and the relationship to exercise capacity in a cohort of COPD patients.

Methods: Thirty-two subjects gave consent (53\% male, with mean \pm standard deviation age $66 \pm 9$ years, smoking $35 \pm 29$ pack-years, and Global Initiative for Chronic Obstructive Lung Disease (GOLD) classification of 0-4: 2.3 \pm 0.8 ), filled out the St George's Respiratory Questionnaire (SGRQ) to measure quality of life, had a complete blood count drawn, and underwent spirometry. The intrabreath (IB) technique for lung diffusing capacity for carbon monoxide (IBDLCO) and pulmonary blood flow (IBQc, at rest) was also performed. Subsequently, they completed a cycle ergometry test to exhaustion with measures of oxygen saturation and expired gases.

Results: Baseline average measures were $44 \pm 21$ for SGRQ score and $58 \pm 11$ for $\mathrm{FEV}_{1} / \mathrm{FVC}$. Peak oxygen consumption $\left(\mathrm{VO}_{2}\right)$ was $11.4 \pm 3.1 \mathrm{~mL} / \mathrm{kg} / \mathrm{min}$ ( $49 \%$ predicted). The mean resting IBDLCO was $9.7 \pm 5.4 \mathrm{~mL} / \mathrm{min} / \mathrm{mmHg}$ and IBQc was $4.7 \pm 0.9 \mathrm{~L} / \mathrm{min}$. At the first workload, heart rate (HR) increased to $92 \pm 11 \mathrm{bpm}, \mathrm{VO}_{2}$ was $8.3 \pm 1.4 \mathrm{~mL} / \mathrm{kg} / \mathrm{min}$, and IBDLCO and IBQc increased by $46 \%$ and $43 \%$, respectively, compared to resting values $(p<0.01)$. The IBDLCO/ Qc ratio averaged 2.0 \pm 1.1 at rest and remained constant during exercise with marked variation across subjects (range: $0.8-4.8$ ). Ventilatory efficiency plateaued at $37 \pm 5$ during exercise, partial pressure of mix expired $\mathrm{CO}_{2}$ /partial pressure of end tidal $\mathrm{CO}_{2}$ ratio ranged from 0.63 to 0.67 , while a noninvasive index of pulmonary capacitance, $\mathrm{O}_{2}$ pulse $\times \mathrm{PetCO}_{2}(\mathrm{GxCap})$ rose to $138 \%$. The exercise IBDLCO/Qc ratio was related to $\mathrm{O}_{2}$ pulse $\left(\mathrm{VO}_{2} / \mathrm{HR}, r=0.58, p<0.01\right)$, and subjects with the highest exercise IBDLCO/Qc ratio or the greatest rise from rest had the highest peak $\mathrm{VO}_{2}$ values ( $r=0.65$ and 0.51 , respectively, $p<0.05$ ). Of the noninvasive gas exchange measures of pulmonary vascular function, GxCap was most closely associated with $\mathrm{DLCO}, \mathrm{DLCO} / \mathrm{Qc}$, and $\mathrm{VO}_{2}$ peak.

Conclusion: COPD patients who can expand gas exchange surface area as assessed with DLCO during exercise relative to pulmonary blood flow have a more preserved exercise capacity.

Keywords: airflow limitation, exercise intolerance, lung gas transfer, dyspnea, COPD, diffusion capacity, cardiopulmonary exercise testing

\section{Introduction}

Exercise stresses our physiological reserve by increasing muscular contraction and the demand for blood flow and ventilation to maintain gas exchange. ${ }^{1}$ As cardiac output rises, the typically compliant pulmonary vascular bed expands to increase lung surface 
area while at the same time retaining a low pressure system for the efficient forward blood flow. In health, this expansion of the alveolar-capillary layer results in a nearly linear rise in lung diffusing capacity for carbon monoxide (DLCO) with cardiac output (Q) as exercise intensity increases. ${ }^{2}$

In patients with COPD, as destruction of the alveolarcapillary bed occurs, areas of ventilation and perfusion mismatch create hypoxic constriction of pulmonary vessels. Furthermore, airway obstruction increases intrathoracic pressure influencing venous return to the right side of the heart. ${ }^{3}$ Remodeling of the pulmonary capillaries may also occur resulting in stiffer vessels. Thus, as the disease pathophysiology progresses, the process limits the ability of the alveolarcapillary bed to expand and potentially not only limits the rise in gas exchange surface area but also creates an impediment to forward blood flow or cardiac output, which could ultimately contribute to exercise intolerance in this population.

Physiology of exercise in COPD has been a topic of great interest. Previous work by Potter $^{3}$ suggested that the degree of airway obstruction during exercise may result in a blunted rise in cardiac output presumably due to the large rise in expiratory intrathoracic pressures, while Montes de $\mathrm{Oca}^{4}$ demonstrated an association of oxygen pulse, a surrogate for stroke volume, with exercise capacity in COPD patients. Similarly, Fuji ${ }^{5}$ suggested that a higher slope of change in pulmonary arterial pressure relative to the change in $\mathrm{Q}$ was associated with a reduced exercise capacity. We and others have previously demonstrated that resting DLCO is predictive of exercise capacity in a COPD population and more significantly so when accounting for the resting pulmonary blood flow (Qc), or essentially the functional lung surface area for gas exchange relative to cardiac output. ${ }^{6}$ The DLCO is highly dependent on Q, and to date, most studies suggest a strong linear relationship between the two with no evidence of a DLCO plateau during heavy exercise even in highly fit individuals. ${ }^{7}$ Since a rise in cardiac output is the main determinant of pulmonary capillary recruitment, the DLCO relationship relative to $\mathrm{Q}$ gives a good overall estimate of the ability to expand this vascular bed.

Therefore, the focus of this study was to quantify DLCO at rest and during exercise using the intrabreath method in a moderate-to-severe COPD population (functional alveolar-capillary recruitment). We hypothesized that the subjects who could increase DLCO in proportion to the rise in Qc (maintenance of the relationship) would have a more preserved exercise capacity. We preferred the intrabreath over the single-breath DLCO (SBDLCO) technique because the latter is difficult to perform with a 10 -s breath hold in dyspneic COPD patients at rest and more so during exercise. The intrabreath technique has been compared to other techniques such as the rebreathe or open circuit and has been validated. ${ }^{8-10}$

An additional goal of our study was to analyze the relationship of DLCO and Qc to other noninvasive measures of respiratory gas exchange that have been associated with pulmonary vascular function. These included ventilatory efficiency, partial pressure of mix expired $\mathrm{CO}_{2}\left(\mathrm{PeCO}_{2}\right)$ / partial pressure of end tidal $\mathrm{CO}_{2}\left(\mathrm{PetCO}_{2}\right)$ ratio, as well as a more novel measure previously associated with pulmonary vascular capacitance in the heart failure population, $\mathrm{O}_{2}$ pulse $\times \mathrm{PetCO}_{2}(\mathrm{GxCap}) .{ }^{11-13}$

\section{Methods}

\section{Ethics and consent}

The study, ethics, and consent forms were reviewed and approved by the Western Institutional Review Board (WIRB, study number 1153374).

\section{Subjects}

Patients with a history of COPD who were sent for clinical pulmonary function testing (PFT) and/or exercise testing were offered enrollment. Inclusion criteria was a history of moderate-to-severe COPD using the Global Initative for Chronic Obstructive Lung Disease (GOLD) criteria. Exclusion criteria included an inability to exercise, dependence on home oxygen therapy, or a body mass index $(\mathrm{BMI})>42$. Prior to participation, the study goals and requirements were reviewed with the patients. If willing to participate, subjects signed informed consent.

\section{Overview of study}

After reporting to the outpatient clinic, study participants filled out the St George's Respiratory Questionnaire (SGRQ) to measure quality of life (QOL) and performed PFTs which included resting measures of maximal lung volumes and flow rates using classical spirometry. ${ }^{14,15}$ In addition, the assessment of DLCO was obtained using the classical SBDLCO technique and was also obtained using the intrabreath DLCO method (IBDLCO) which also included a measure of Qc. ${ }^{16}$ A small blood sample was obtained prior to testing for assessment of hemoglobin in order to correct the measures of DLCO. Subjects subsequently performed cardiopulmonary exercise testing (CPET) using the CareFusion metabolic cart (San Diego, CA, USA) on a semi-recumbent cycle ergometer (Lode, Groningen, the Netherlands). The test protocol started with $20 \mathrm{~W}$ for both men and women and increased 
by $10 \mathrm{~W}$ every $2 \mathrm{~min}$. Prior to exercise testing, subjects were instrumented with a 12-lead ECG and a forehead pulse oximeter for peripheral arterial oxygen saturation $\left(\mathrm{SaO}_{2}\right)$ for continuous monitoring. Subjects wore a nose clip and breathed on a mouthpiece for measurement of gas exchange during the exercise test. During the last $30 \mathrm{~s}$ of each workload, a 12-lead ECG was recorded, blood pressure (BP) was assessed, and an average of the heart rate (HR) and $\mathrm{SaO}_{2}$ over this period was determined. We assessed the patient dyspnea by the Borg scale (on the 0-10 scale) and the total body effort by the rated perceived exertion (RPE) score (on the Borg 6-20 scale). Subjects were encouraged to exercise to near exhaustion by achieving an RPE of 17-18 or a dyspnea score $\geq 7$. Upon reaching peak exercise, subjects performed active recovery where they continued to pedal with no resistance and remained on the mouthpiece for $1 \mathrm{~min}$. After this, the subjects stopped pedaling and were given time for HR and BP to return to baseline before being dismissed.

\section{Pulmonary function and single-breath DLCO}

Spirometry was performed using pneumotachograph-based pulmonary function equipment by CareFusion that had passed evaluation using 24 waveforms recommended by the American Thoracic Society (ATS). Classic resting SBDLCO was determined using CareFusion instrument following the recommendations of the ATS/ERS. ${ }^{17,18}$

\section{Intrabreath lung diffusing capacity and Qc}

Qc and DLCO were measured using inert and soluble gases on the CareFusion Vmax system using the intrabreath method. ${ }^{16,19}$ For this method, subjects were asked to breathe on a mouthpiece while wearing a nose clip. Subjects were instructed to exhale to near residual volume (RV) and then were switched into an inspiratory reservoir and took a full inhalation of a test gas mixture containing $0.3 \%$ carbon monoxide (CO), $0.3 \%$ methane, $0.3 \%$ acetylene, $21 \% \mathrm{O}_{2}$, and balance $\mathrm{N}_{2}$. Subjects were trained to exhale at a steady rate until they were back near RV. From the rate of disappearance of $\mathrm{CO}$ and acetylene in comparison with the inert gas methane, the rate of disappearance of $\mathrm{CO}$ and acetylene was determined. This rate of disappearance of $\mathrm{CO}$ was used to calculate IBDLCO. Since acetylene does not bind to hemoglobin, the rate of its disappearance is limited primarily by the flow of blood through the lungs, thereby providing a measure of Qc. ${ }^{16,20}$ The measure of IBDLCO and IBQc was practiced several times at rest in each subject until reproducible values were obtained and performed near the end of the first workload in triplicate. If necessary, the first workload was extended before incrementing the cycle ergometer resistance in order to obtain reproducible measures.

\section{QOL Questionnaires - SGRQ}

The SGRQ is a 50-item questionnaire developed to measure health status (QOL) in patients with diseases causing airway obstruction. Scores are calculated for three domains: symptoms, activity, and impacts (psychosocial) as well as a total score. Psychometric testing has demonstrated its repeatability, reliability, and validity. Sensitivity has been demonstrated in clinical trials. ${ }^{14}$ Each patient was asked to fill out the SGRQ questionnaire prior to CPET.

\section{Gas exchange, ventilation, and lung mechanics}

During exercise testing, oxygen consumption $\left(\mathrm{VO}_{2}\right)$, carbon dioxide production $\left(\mathrm{VCO}_{2}\right)$, breathing frequency $(\mathrm{fb})$, tidal volume $\left(\mathrm{V}_{\mathrm{t}}\right)$, minute ventilation $\left(\mathrm{V}_{\mathrm{E}}\right)$, and derived variables were measured continuously and/or calculated using a low-resistance open circuit automated metabolic system (CareFusion).

In addition, measures associated with ventilation and perfusion matching or pulmonary vascular health were determined. One of the measures was $\mathrm{PeCO}_{2}$ relative to $\mathrm{PetCO}_{2}$ which is associated with ventilation and perfusion matching in the lungs and reported to be reduced in COPD patients having pulmonary hypertension with a negative slope during exercise. The other gas exchange measure was GxCap which is a noninvasive estimate of pulmonary vascular capacitance calculated as oxygen pulse multiplied by $\mathrm{PetCO}_{2}$. Oxygen pulse tracks stroke volume and $\mathrm{PetCO}_{2}$ has been shown to reasonably track pulmonary arterial pressure. The last of the measures was ventilatory efficiency or $\mathrm{V}_{\mathrm{E}} / \mathrm{VCO}_{2} \cdot{ }^{11,13}$

\section{Statistics}

We were interested in exercise limitation in the COPD population and the potential role of the alveolar-capillary bed, the lung surface area for gas exchange, or the ability to expand this bed as a mediating factor. Thus, our primary measures were the change in IBDLCO and the change in IBDLCO in proportion to IBQc across subjects and the relationship to exercise or aerobic capacity - primarily peak $\mathrm{VO}_{2}$. Thus, we used multiple regression and correlational analysis to asses these relationships. In addition, general descriptive statistics were used to define our group and paired $t$-tests were used to further analyze changes with exercise. 


\section{Results}

\section{Subject characteristics and resting pulmonary function}

Thirty-two subjects completed all aspects of the study (age $66 \pm 9$ years, $53 \%$ male, smoking history $35 \pm 29$ pack-years, BMI $30 \pm 6 \mathrm{~kg} / \mathrm{m}^{2}$; mean \pm SD). The study cohort consisted of primarily moderate COPD patients based on the GOLD classification (2.3 \pm 0.8$)$, but with some subjects mild and others more severe (GOLD classification range: 1-4). This degree of disease was reflected in the QOL scores (SGRQ averaged $44 \pm 21$ ) and medication use with the majority of patients on multiple inhalers and with $20 \%$ on oral steroids. None of the subjects were on continuous oxygen at the time of the study. Hemoglobin values were essentially within normal limits and averaged $13.5 \pm 1.7 \mathrm{~g} / \mathrm{dL}$.

The forced vital capacity (FVC) averaged $2.48 \pm 0.69 \mathrm{~L}$ or $75 \%$ of age and gender predicted, while the forced expiratory volume in $1 \mathrm{~s}\left(\mathrm{FEV}_{1}\right)$ averaged $56 \% \pm 16 \%$ of predicted with an $\mathrm{FEV}_{1} / \mathrm{FVC}$ ratio of $58 \% \pm 11 \%$, range $33 \%-78 \%$. The $\mathrm{FEF}_{25-75}$ averaged $0.75 \pm 0.38 \mathrm{~L}$ or $26 \% \pm 13 \%$ of predicted. The SBDLCO averaged $13.2 \pm 5.5 \mathrm{~mL} / \mathrm{min} / \mathrm{mmHg}$ and $58 \% \pm 23 \%$ of age and gender predicted. Both the SGRQ score and the GOLD classification were somewhat associated with resting DLCO ( $\mathrm{r}$ values ranging from 0.33 to 0.38 ).

\section{Cardiopulmonary exercise responses}

Cardiopulmonary responses to exercise are shown in Table 1 . The most common symptoms for stopping exercise were dyspnea, general fatigue, and leg fatigue. Peak work achieved was $43 \mathrm{~W}$ with a $\mathrm{VO}_{2}$ peak of $11.4 \mathrm{~mL} / \mathrm{kg} / \mathrm{min}$ or $49 \%$ of age and gender predicted. Peak HR was 106 bpm or $70 \%$ of age predicted. Tidal volume increased early in exercise but then plateaued as ventilation was primarily rate dependent beyond the first workload. Peak minute ventilation reached $70 \%$ of the estimated breathing capacity and inspiratory capacity (IC) fell throughout exercise suggesting expiratory flow limitation and some hyperinflation as exercise progressed. Oxygen pulse rose to $7.8 \mathrm{~mL}$ per beat by the first exercise load, but then rose slowly thereafter.

Ventilatory efficiency assessed as the $\mathrm{V}_{\mathrm{E}} / \mathrm{VCO}_{2}$ ratio was elevated at rest and fell with exercise but stayed elevated without a clear exercise nadir. The $\mathrm{PeCO}_{2} / \mathrm{PetCO}_{2}$ ratio started at 0.54 at rest and stayed below a ratio of 0.70 throughout exercise. The gas exchange estimate of pulmonary capacitance, GxCap, on average increased 138\% from rest to peak exercise but plateaued or declined in approximately half $(47 \%)$ of the subjects over the last two workloads.
Table I Cardiopulmonary responses to exercise in COPD patients $(\mathrm{N}=32)$

\begin{tabular}{|c|c|c|c|c|}
\hline & Rest & $\begin{array}{l}\text { First } \\
\text { workload }\end{array}$ & $\begin{array}{l}70 \%-90 \% \\
\text { of peak }\end{array}$ & Peak \\
\hline \multicolumn{5}{|l|}{ Exercise capacity } \\
\hline Work (W) & 0 & $18 \pm 4$ & $33 \pm 14$ & $43 \pm 19$ \\
\hline $\mathrm{VO}_{2}(\mathrm{~mL} / \mathrm{kg} / \mathrm{min})$ & $3.66 \pm 0.84$ & $8.34 \pm 1.40$ & $10.00 \pm 2.50$ & $11.40 \pm 3.12$ \\
\hline \multicolumn{5}{|l|}{ Symptoms } \\
\hline RPE (6-20 Borg Score) & $7 \pm 2$ & $11 \pm 3$ & $15 \pm 3$ & $17 \pm 2$ \\
\hline Dyspnea (0-10 Score) & $I \pm I$ & $3 \pm 2$ & $5 \pm 2$ & $7 \pm 2$ \\
\hline \multicolumn{5}{|l|}{ Cardiovascular } \\
\hline Heart rate (bpm) & $77 \pm 10$ & $92 \pm 11$ & $100 \pm 11$ & $106 \pm 12$ \\
\hline $\mathrm{O}_{2}$ pulse $\left(\mathrm{VO}_{2} / \mathrm{HR}\right)$ & $4.1 \pm 0.9$ & $7.8 \pm 2.1$ & $8.9 \pm 2.7$ & $9.3 \pm 3.1$ \\
\hline $\mathrm{SBP}(\mathrm{mmHg})$ & $118 \pm 24$ & $137 \pm 17$ & $146 \pm 20$ & $|52 \pm 2|$ \\
\hline $\mathrm{DBP}(\mathrm{mmHg})$ & $73 \pm 10$ & $82 \pm 11$ & $86 \pm 10$ & $88 \pm 11$ \\
\hline \multicolumn{5}{|c|}{ Ventilation and breathing pattern } \\
\hline Ventilation (L/min) & $12 \pm 3$ & $24 \pm 6$ & $28 \pm 9$ & $34 \pm 10$ \\
\hline Tidal volume $(L)$ & $0.79 \pm 0.17$ & $1.13 \pm 0.37$ & I. $15 \pm 0.36$ & $1.17 \pm 0.37$ \\
\hline $\begin{array}{l}\text { Breathing frequency } \\
\text { (bpm) }\end{array}$ & $18 \pm 6$ & $25 \pm 7$ & $28 \pm 7$ & $3 I \pm 5$ \\
\hline IC (L) & $2.15 \pm 0.67$ & $|.89 \pm 0.7|$ & $1.78 \pm 0.83$ & $1.70 \pm 0.69$ \\
\hline$V_{t} / I C$ & $37 \pm 13$ & $52 \pm 12$ & $61 \pm 25$ & $65 \pm 27$ \\
\hline $\begin{array}{l}\mathrm{V}_{\mathrm{E}} / \text { breathing } \\
\text { capacity (\%) }\end{array}$ & $27 \pm 9$ & $5 I \pm 25$ & $58 \pm 21$ & $69 \pm 21$ \\
\hline \multicolumn{5}{|c|}{ Gas exchange - pulmonary vascular } \\
\hline $\mathrm{V}_{\mathrm{E}} / \mathrm{VCO}_{2}$ ratio & $47 \pm 7$ & $37 \pm 5$ & $37 \pm 5$ & $36 \pm 5$ \\
\hline $\mathrm{PetCO}_{2}(\mathrm{mmHg})$ & $35 \pm 5$ & $37 \pm 5$ & $37 \pm 5$ & $37 \pm 5$ \\
\hline $\mathrm{PeCO}_{2}(\mathrm{mmHg})$ & $19 \pm 3$ & $23 \pm 3$ & $24 \pm 3$ & $24 \pm 3$ \\
\hline $\mathrm{PeCO}_{2} / \mathrm{PetCO}_{2}$ ratio & $0.54 \pm 0.04$ & $0.63 \pm 0.05$ & $0.66 \pm 0.06$ & $0.67 \pm 0.06$ \\
\hline GxCap & $143 \pm 40$ & $289 \pm 85$ & $317 \pm 102$ & $34 I \pm 116$ \\
\hline
\end{tabular}

Notes: Data shown as mean \pm standard deviation.

Abbreviations: DBP, diastolic blood pressure; fb, breathing frequency; GxCap, $\mathrm{O}_{2}$ pulse $\times \mathrm{PetCO}_{2}$; HR, heart rate; IC, inspiratory capacity; $\mathrm{O}_{2}$ pulse, $\mathrm{VO}_{2} /$ heart rate; $\mathrm{PeCO}_{2}$, partial pressure of mix expired $\mathrm{CO}_{2}$; $\mathrm{PetCO}$, partial pressure of end tidal $\mathrm{CO}_{2}$; RPE, rated perceived exertion; $\mathrm{SaO}_{2}$, arterial oxygen saturation estimated from pulse oximetry; SBP, systolic blood pressure; TI, inspiratory time; TTOT, total respiratory cycle time; $\mathrm{VCO}_{2}$, carbon dioxide production; $\mathrm{V}_{\mathrm{E}}$, minute ventilation; $\mathrm{VO}_{2}$, oxygen consumption; $\mathrm{V}_{\mathrm{t}}$, tidal volume.

\section{Measures of DLCO and pulmonary blood flow}

The changes in DLCO, Qc, stroke volume, and DLCO relative to Qc are shown in Table 2. Individual changes in DLCO and DLCO/Qc from rest to the first workload are shown in Figures 1 and 2. On average, DLCO increased 45\% from rest to the first workload. However, there was large variation in responses with three subjects demonstrating $>10 \%$ fall in DLCO and another four subjects demonstrating minimal change with exercise. Pulmonary blood flow increased on average $40 \%$ during the first workload, while stroke volume increased $18 \%$. The mean IBDLCO relative to Qc (DLCO/Qc) stayed relatively constant with exercise increasing on average $14 \%$ from rest to the first workload while the majority of subjects demonstrated a rise in this ratio, 12 of the subjects had no change or had a fall, suggesting Qc was 
Table 2 Intrabreath lung diffusing capacity and pulmonary blood flow at rest and during exercise in COPD patients $(\mathrm{N}=32)$

\begin{tabular}{lclll}
\hline & Rest & $\begin{array}{l}\text { First } \\
\text { workload }\end{array}$ & $\begin{array}{l}\% \text { change } \\
\text { Range, } \\
\% \text { change }\end{array}$ \\
\hline $\begin{array}{l}\text { IBDLCO } \\
(\mathrm{mL} / \mathrm{min} / \mathrm{mmHg})\end{array}$ & $9.6 \pm 5.9$ & $13.3 \pm 7.1$ & $45 \% \pm 44 \%$ & $-22 \%$ to $137 \%$ \\
$\begin{array}{l}\mathrm{IBQc}, \mathrm{L} / \mathrm{min} * \\
\text { Cardiac stroke }\end{array}$ & $4.8 \pm 0.9$ & $6.6 \pm 1.4$ & $40 \% \pm 28 \%$ & $0.6 \%$ to $123 \%$ \\
$\begin{array}{l}\text { volume }(\mathrm{mL}) \\
\text { IBDLCO/IBQc }\end{array}$ & $62 \pm 14$ & $73 \pm 20$ & $18 \pm 23$ & $36 \%$ to $133 \%$ \\
\hline
\end{tabular}

Notes: Data shown as mean \pm standard deviation. ${ }^{*} \mathrm{Qc}$ measured with soluble gas method.

Abbreviations: DLCO, lung diffusing capacity for carbon monoxide; IB, intrabreath technique; Qc, pulmonary blood flow.

increasing out of proportion to lung surface area for gas exchange in these subjects.

\section{Respiratory measures associated with lung diffusion}

We were interested in the relationship of other noninvasive indices associated with pulmonary vascular function and lung diffusion during exercise. Ventilatory efficiency for carbon dioxide, $\left(\mathrm{V}_{\mathrm{E}} / \mathrm{VCO}_{2}\right)(r=-0.44)$, the mixed expired-to-end tidal $\mathrm{CO}_{2}$ ratio, $\left(\mathrm{PeCO}_{2} / \mathrm{PetCO}_{2}\right)(r=0.40)$, and $\mathrm{GxCap}$ were all associated with the exercise IBDLCO measure $(p<0.05)$. However, the GxCap was the gas exchange measure mostly associated with exercise IBDLCO (Figure 3) $(r=0.71)$.

\section{Relationship of lung diffusion, pulmonary blood flow, and indices of pulmonary vascular function to exercise capacity}

The exercise IBDLCO and change from rest in the IBDLCO were only marginally associated with $\mathrm{VO}_{2}$ peak $(r=0.43$ and $0.39, p<0.05$ ), while the relationship of exercise DLCO/Qc or the change in $\mathrm{DLCO} / \mathrm{Qc}$ to $\mathrm{VO}_{2}$ peak was more strongly

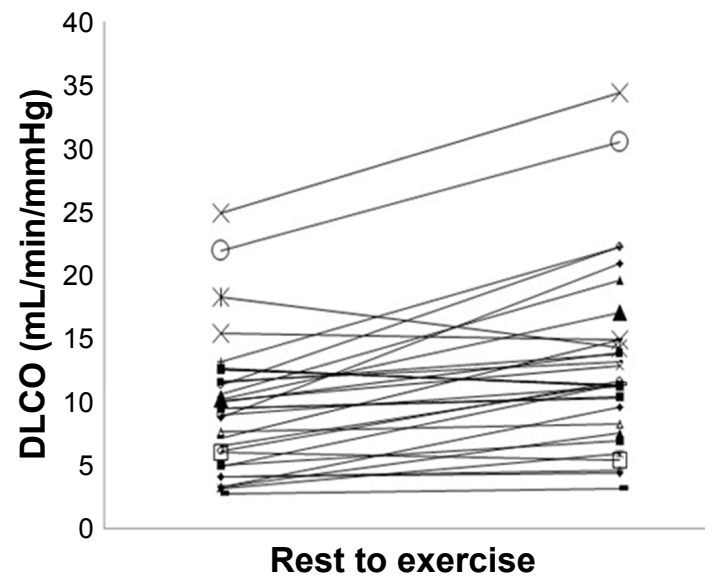

Figure I Change in intrabreath DLCO from rest to first stage of exercise in patients with COPD.

Abbreviation: DLCO, diffusing capacity for carbon monoxide.

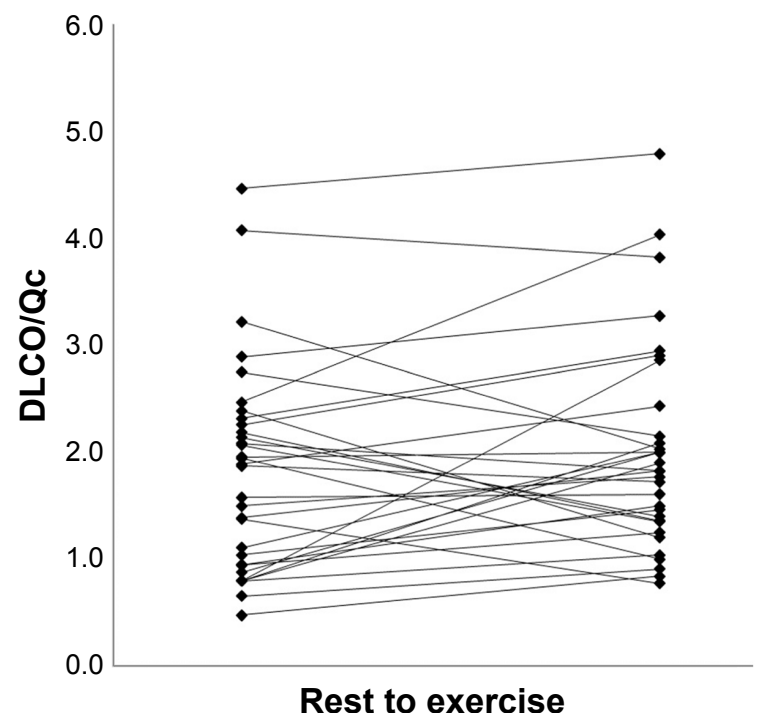

Figure 2 Change in intrabreath DLCO relative to Qc from rest to first exercise workload in patients with COPD.

Abbreviations: DLCO, diffusing capacity for carbon monoxide; Qc, pulmonary blood flow measured with soluble gas method.

related ( $r=0.63$ and 0.54 , respectively, $p<0.01$ ). Figure 4 shows the relationship of $\mathrm{VO}_{2}$ peak and $\mathrm{VCO}_{2}$ peak with $\mathrm{DLCO} / \mathrm{Q}$. The modest correlation with these measures suggests that subjects with the greatest recruitment in lung gas exchange surface area relative to pulmonary blood flow were the subjects with the best exercise tolerance. With multiple regression including IBDLCO, the change in IBDLCO and $\mathrm{DLCO} / \mathrm{Qc}$, the DLCO/Qc from rest to exercise was the measure most significantly associated with $\mathrm{VO}_{2}$ peak. DLCO/ Qc was also associated with $\mathrm{O}_{2}$ pulse $(r=0.63)$. Furthermore, exercise capacity was associated with the $\mathrm{PeCO}_{2} / \mathrm{PetCO}_{2}$ ratio with those with higher ratios having better exercise toler-

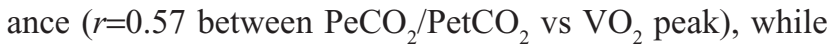
both the absolute measure of GxCap during exercise and the change from rest to peak exercise being associated with

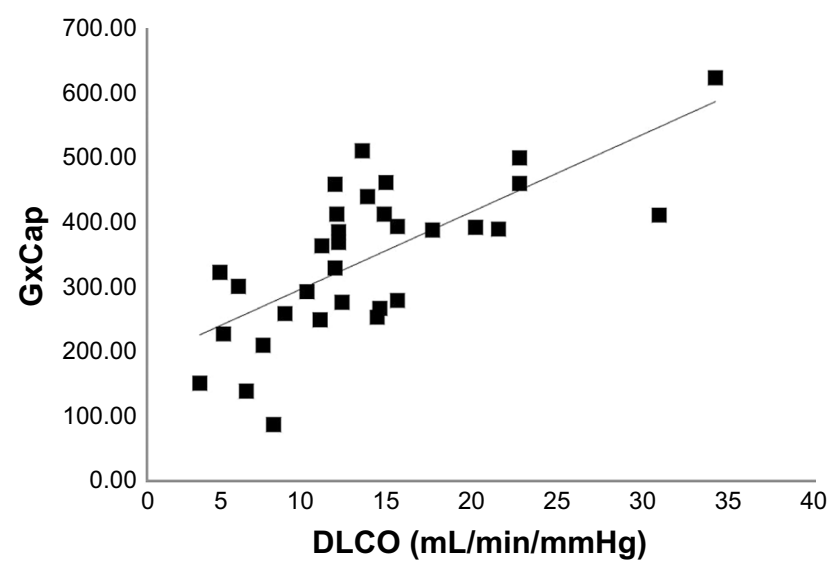

Figure 3 Relationship of GxCap to DLCO in COPD patients.

Abbreviations: DLCO, diffusing capacity for carbon monoxide; GxCap, $\mathrm{O}_{2}$ pulse $\times$ PetCO $;$; PetCO , partial pressure of end tidal $\mathrm{CO}_{2}$. 

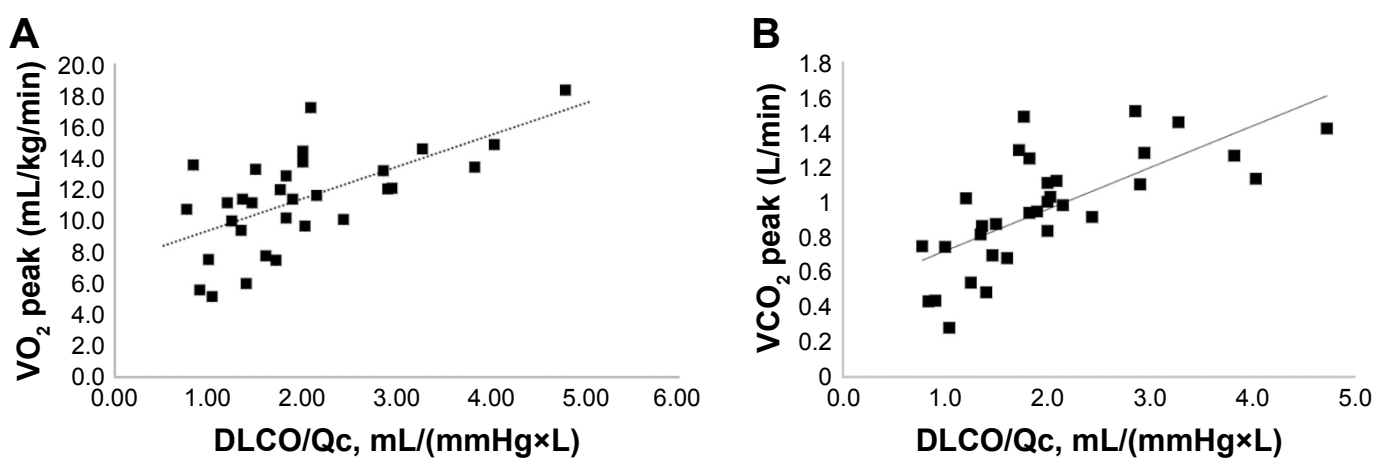

Figure 4 Relationship of $\mathrm{VO}_{2}$ peak (A) and $\mathrm{VCO}_{2}$ peak (B) with DLCO/Qc.

Abbreviations: DLCO, diffusing capacity for carbon monoxide; $\mathrm{Qc}$, pulmonary blood flow; $\mathrm{VCO}_{2}$, carbon dioxide production; $\mathrm{VO}_{2}$, oxygen consumption.

$\mathrm{VO}_{2}$ peak ( $r=0.53$ and 0.66 , respectively, $p<0.01$, Figure 5 ). The lung function measure most associated with DLCO or $\mathrm{DLCO} / \mathrm{Qc}$ during exercise was the exercise IC ( $r=0.58$ and 0.63 , respectively, $p<0.01$, Figure 6 ).

\section{Discussion}

\section{Primary findings}

Our primary finding was that COPD patients who can increase respiratory gas exchange surface area (ie, alveolarcapillary reserve - as assessed by DLCO) relative to the rise in Qc have the most preserved exercise capacity. In addition, the ability to expand the pulmonary vascular bed is associated with noninvasive indices of pulmonary capacitance as well as with IC assessed during exercise. While these data are correlative, this implies that a contributing factor to exercise intolerance in this population may be the inability to recruit pulmonary capillaries.

\section{Pulmonary vasculature in COPD}

The majority of our patients had a history of smoking as the likely primary etiology of their airway disease. Years of

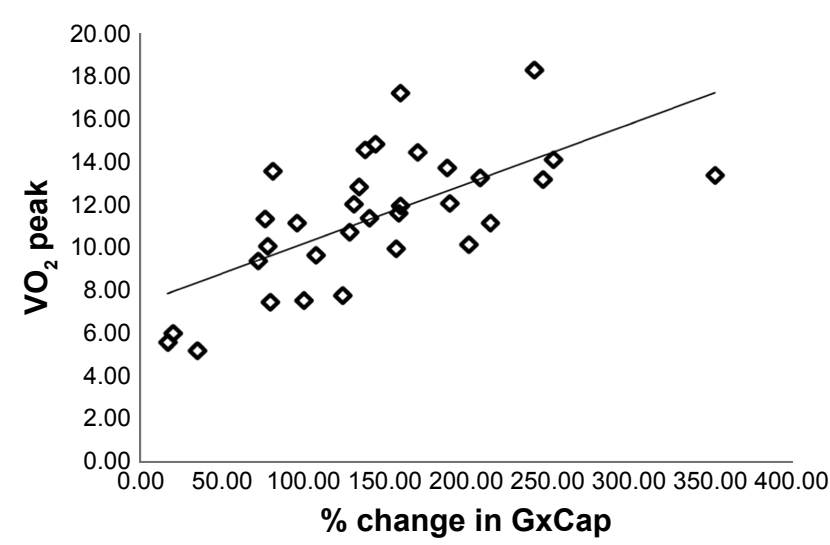

Figure 5 Relationship of $\mathrm{VO}_{2}$ with the change in $\mathrm{GxCap}$ from rest to peak exercise. Abbreviations: $\mathrm{G} \times \mathrm{Cap}, \mathrm{O}_{2}$ pulse $\times \mathrm{PetCO}_{2} ; \mathrm{PetCO}_{2}$, partial pressure of end tidal $\mathrm{CO}_{2} ; \mathrm{VO}_{2}$, oxygen consumption. exposure to inhalants causes destruction and remodeling of the alveolar-capillary bed, accelerated aging, inflammation, and other chronic metabolites that circulate to cause a general vasculopathy and stiffening of vessels. ${ }^{21-23}$ There are often regions of inhomogeneous pulmonary vasoconstriction due to the ventilation and perfusion abnormalities. All of these factors contribute to a blunted ability to increase or expand the alveolar-capillary bed. Previous work has suggested that ${ }^{5}$ an abnormal rise in pulmonary arterial pressure relative to the rise in cardiac output was associated with reduced exercise performance in COPD patients and presumably a resistance to forward flow through the lungs - thus a form of cardiac output limitation. ${ }^{5}$ However, $\mathrm{VO}_{2}$ peak was not related to the degree of airflow obstruction in this study which is an interesting finding. Other studies have also suggested a strong relationship between exercise capacity and oxygen pulse, a surrogate for stroke volume. ${ }^{4}$ In addition, airway obstruction itself causes an increase in intrathoracic pressure that may act as an impediment to venous return - potentially further

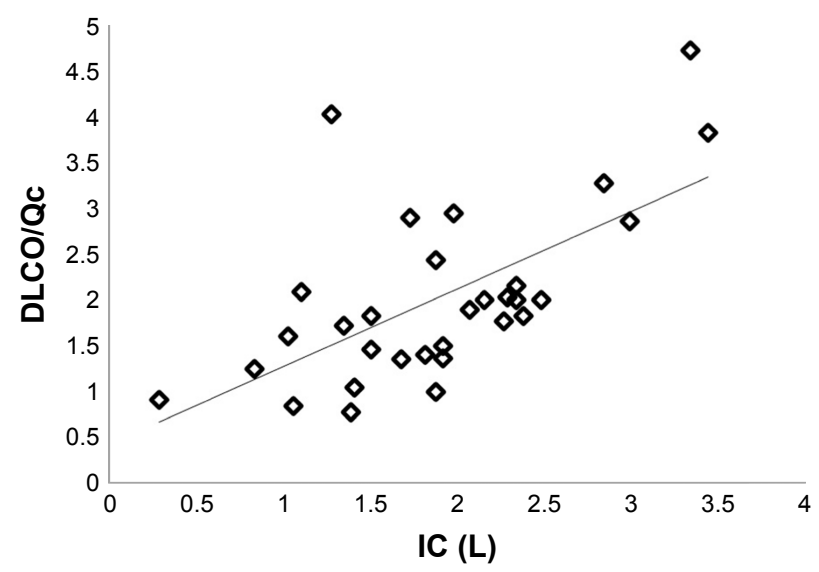

Figure 6 Relationship of DLCO/Qc relative to IC. Note: Qc measured with soluble gas method.

Abbreviations: DLCO, diffusing capacity for carbon monoxide; IC, inspiratory capacity; Qc, pulmonary blood flow. 
influencing cardiac output. ${ }^{3}$ While we did not directly measure hemodynamics, there is typically a strong linear relationship between DLCO and Q in healthy individuals showing a steady and proportional increase with moderateto-heavy exercise. Presumably, this represents recruitment and distension of the pulmonary capillaries. Since DLCO is flow independent, a rise in DLCO is primarily influenced by the expansion of this bed. Thus, our measure of DLCO/Qc would primarily represent a rise in pulmonary capillary blood volume that is in contact with functional alveoli. While, on average, DLCO did rise with exercise and DLCO relative to Qc $(\mathrm{DLCO} / \mathrm{Qc})$ stayed relatively constant, there were a large number of subjects (38\%) where this ratio plateaued or fell with exercise, suggesting that as pulmonary blood flow increased, there was a non-proportional increase in gas exchange surface area. ${ }^{24}$

\section{DLCO relative to other respiratory gas exchange measures in COPD}

We also assessed several other reported respiratory gas exchange measures associated with ventilation and perfusion matching and pulmonary vascular function. Ventilatory efficiency $\left(\mathrm{V}_{\mathrm{E}} / \mathrm{VCO}_{2}\right)$, the partial pressure of $\mathrm{CO}_{2}$ relative to end tidal $\mathrm{CO}_{2}\left(\mathrm{PeCO}_{2} / \mathrm{PetCO}_{2}\right)$, and an index of pulmonary vascular capacitance (GxCap) are all associated with lung diffusing capacity. ${ }^{13}$ Ventilatory efficiency is commonly reported elevated in patients with pulmonary vascular disease and is associated with high dead space ventilation, hyperventilation, and a rapid shallow breathing pattern. ${ }^{25}$ The $\mathrm{PeCO}_{2} / \mathrm{PetCO}_{2}$ ratio and the slope of change from rest to exercise have been suggested to differ between primarily pulmonary vascular disease versus conditions of more ventilation and perfusion mismatch, with lower ratios suggesting worsening disease. Furthermore, GxCap has previously been shown to correlate well with invasive measures of pulmonary vascular capacitance. ${ }^{13}$ It is interesting that while all these measures were associated with DLCO, the GxCap measure was the most significantly linked both to DLCO and to peak exercise performance. The premise is that oxygen pulse tends to track stroke volume changes, while $\mathrm{PetCO}_{2}$ tends to fall with greater pulmonary vascular pressures in conditions like pulmonary hypertension - thus a surrogate for pressure. Thus, since the DLCO is essentially dependent on the recruitment and distension of the pulmonary capillaries, it essentially should increase with greater pulmonary vascular capacitance. While both increased with exercise, there were a significant number of subjects where these rose minimally or failed to increase.

\section{Previous studies looking at exercise intolerance in COPD}

A number of studies have demonstrated a clear impact of airway obstruction on exercise performance. ${ }^{26-28}$ However, as the disease progresses, it clearly becomes a systemic disease impacting many organ systems. Previous work by O'Donnell has demonstrated an association with the degree of hyperinflation and that improvement of obstruction with bronchodilators clearly enhances exercise capacity. ${ }^{29}$ In addition, muscle dysfunction, muscle wasting, and deconditioning also begin to develop..$^{30,31}$ It is clear that COPD is not a homogeneous disease, and thus, it is likely that multiple issues contribute to the loss of exercise capacity. Our study highlights the importance of the pulmonary vasculature in determining exercise tolerance in this chronic disease state.

\section{Limitations and conclusion}

There are a number of potential study limitations. First, the population was small, and thus, general conclusions are limited. Second, we only assessed DLCO during the first exercise load. While we attempted to measure this at other work levels and got success in some cases, we felt confident only in our data at the lower work level. Subjects were trained to perform the maneuver reproducibly at rest and typically performed three reproducible maneuvers at the lower workloads, but struggled to perform them reproducibly at the higher work intensities. Thus, we were examining their ability to recruit lung alveolar-capillary surface area with relatively modest workloads and comparing these data to their peak aerobic capacity. However, the DLCO response to exercise should be relatively linear with workload, $\mathrm{VO}_{2}$, and cardiac output, and thus, the ability to expand the pulmonary circulation early in exercise is likely representative of their reserve with heavier activity. The first workload also represented on average nearly $75 \%$ of peak $\mathrm{VO}_{2}$ and thus would be considered a moderately heavy load for this population. Third, we did not have direct measures of pulmonary vascular pressures to better understand the relationships between pulmonary blood flow, pulmonary pressure, and the rise in DLCO which would have given better insight into what was limiting the alveolar-capillary expansion. Finally, there is a baseline degree of deterioration in the alveolar-capillary bed in the COPD population. While DLCO increase is predictive of the ability to exercise more, it does not fully explain the exercise response. Therefore, additional studies are needed to better understand regulating factors in exercise that might improve functional alveolarcapillary surface area. 


\section{Acknowledgments}

The authors thank David Sinks and Beth Anke from CareFusion for their technical support and also Salome Ilkhan, Angie Holland, and other staff in the Cardiopulmonary Exercise lab in Augusta for their assistance in testing and scheduling the patients.

This work was presented as a poster at the CHEST 2016: American College of Chest Physicians Annual Meeting, October 22-26, Los Angeles, CA, USA.

\section{Disclosure}

The authors report no conflicts of interest in this work.

\section{References}

1. Dempsey JA. J.B. Wolffe memorial lecture. Is the lung built for exercise? Med Sci Sports Exerc. 1986;18(2):143-155.

2. Rampulla C, Marconi C, Beulcke G, Amaducci S. Correlations between lung-transfer factor, ventilation, and cardiac output during exercise. Respiration. 1976;33(6):405-415.

3. Potter WA, Olafsson S, Hyatt RE. Ventilatory mechanics and expiratory flow limitation during exercise in patients with obstructive lung disease. J Clin Invest. 1971;50(4):910-919.

4. Montes de Oca M, Rassulo J, Celli BR. Respiratory muscle and cardiopulmonary function during exercise in very severe COPD. Am J Respir Crit Care Med. 1996;154(5):1284-1289.

5. Fujii T, Kurihara N, Fujimoto S, Hirata K, Yoshikawa J. Role of pulmonary vascular disorder in determining exercise capacity in patients with severe chronic obstructive pulmonary disease. Clin Physiol. 1996; 16(5):521-533.

6. Behnia M, Wheatley C, Avolio A, Johnson B. Influence of resting lung diffusion on exercise capacity in patients with COPD. BMC Pulm Med. 2017;17(1):117.

7. Tamhane RM, Johnson RL Jr, Hsia CC. Pulmonary membrane diffusing capacity and capillary blood volume measured during exercise from nitric oxide uptake. Chest. 2001;120(6):1850-1856.

8. Cotton DJ, Prabhu MB, Mink JT, Graham BL. Effect of ventilation inhomogeneity on "intrabreath" measurements of diffusing capacity in normal subjects. J Appl Physiol (1985). 1993;75(2):927-932.

9. Huang YC, O’Brien SR, Vredenburgh J, Folz RJ, Macintyre NR. Intrabreath analysis of carbon monoxide uptake during exercise in patients at risk for lung injury. Respir Med. 2006;100(7):1226-1233.

10. Snyder EM, Johnson BD, Beck KC. An open-circuit method for determining lung diffusing capacity during exercise: comparison to rebreathe. J Appl Physiol (1985). 2005;99(5):1985-1991.

11. Hansen JE, Ulubay G, Chow BF, Sun XG, Wasserman K. Mixed-expired and end-tidal $\mathrm{CO} 2$ distinguish between ventilation and perfusion defects during exercise testing in patients with lung and heart diseases. Chest. 2007;132(3):977-983.

12. Taylor BJ, Johnson BD. The pulmonary circulation and exercise responses in the elderly. Semin Respir Crit Care Med. 2010;31(5): $528-538$.
13. Taylor BJ, Olson TP, Chul Ho K, Maccarter D, Johnson BD. Use of noninvasive gas exchange to track pulmonary vascular responses to exercise in heart failure. Clin Med Insights Circ Respir Pulm Med. 2013; 7:53-60.

14. Meguro M, Barley EA, Spencer S, Jones PW. Development and Validation of an Improved, COPD-Specific Version of the St. George Respiratory Questionnaire. Chest. 2007;132(2):456-463.

15. Rosenberg E. The 1995 update of recommendations for a standard technique for measuring the single-breath carbon monoxide diffusing capacity (transfer factor). Am J Respir Crit Care Med. 1996;154(1):265-266.

16. Charloux A, Enache I, Richard R, et al. Diffusing capacity of the lung for $\mathrm{CO}$ and pulmonary blood flow during incremental and intermittent exercise. Scand J Med Sci Sports. 2010;20(1):e121-e129.

17. Brusasco V, Crapo R, Viegi G, American Thoracic Society, European Respiratory Society. Coming together: the ATS/ERS consensus on clinical pulmonary function testing. Eur Respir J. 2005;26(1):1-2.

18. Macintyre N, Crapo RO, Viegi G, et al. Standardisation of the singlebreath determination of carbon monoxide uptake in the lung. Eur Respir J. 2005;26(4):720-735.

19. Huang YC, O’Brien SR, MacIntyre NR. Intrabreath diffusing capacity of the lung in healthy individuals at rest and during exercise. Chest. 2002;122(1):177-185.

20. Martonen TB, Wilson AF. Theoretical basis of single breath gas absorption tests. J Math Biol. 1982;14(2):203-220.

21. Seeger $\mathrm{W}$, Adir $Y$, Barbera JA, et al. Pulmonary hypertension in chronic lung diseases. J Am Coll Cardiol. 2013;62(25 Suppl):D109-D116.

22. Siafakas NM, Antoniou KM, Tzortzaki EG. Role of angiogenesis and vascular remodeling in chronic obstructive pulmonary disease. Int $J$ Chron Obstruct Pulmon Dis. 2007;2(4):453-462.

23. Vonbank K, Funk GC, Marzluf B, et al. Abnormal pulmonary arterial pressure limits exercise capacity in patients with COPD. Wien Klin Wochenschr. 2008;120(23-24):749-755.

24. Borghi-Silva A, Oliveira CC, Carrascosa C, et al. Respiratory muscle unloading improves leg muscle oxygenation during exercise in patients with COPD. Thorax. 2008;63(10):910-915.

25. Sun XG, Hansen JE, Oudiz RJ, Wasserman K. Exercise pathophysiology in patients with primary pulmonary hypertension. Circulation. 2001; 104(4):429-435.

26. Gallagher CG. Exercise limitation and clinical exercise testing in chronic obstructive pulmonary disease. Clin Chest Med. 1994;15(2):305-326.

27. Johnson BD, Badr MS, Dempsey JA. Impact of the aging pulmonary system on the response to exercise. Clin Chest Med. 1994;15(2):229-246.

28. Pepin V, Saey D, Laviolette L, Maltais F. Exercise capacity in chronic obstructive pulmonary disease: mechanisms of limitation. COPD. 2007; 4(3):195-204.

29. O'Donnell DE, Webb KA. Exertional breathlessness in patients with chronic airflow limitation. The role of lung hyperinflation. Am Rev Respir Dis. 1993;148(5):1351-1357.

30. Aliverti A, Macklem PT. The major limitation to exercise performance in COPD is inadequate energy supply to the respiratory and locomotor muscles. J Appl Physiol (1985). 2008;105(2):749-751. Discussion 755-747.

31. Rodrigues F. Estudo dos factores limitativos do exercicio fisico em doentes com doenca pulmonar obstrutiva cronica [Limiting factors of exercise capacity in patients with COPD]. Rev Port Pneumol. 2004;10(1): 9-61. Portuguese.
International Journal of COPD

\section{Publish your work in this journal}

The International Journal of COPD is an international, peer-reviewed journal of therapeutics and pharmacology focusing on concise rapid reporting of clinical studies and reviews in COPD. Special focus is given to the pathophysiological processes underlying the disease, intervention programs, patient focused education, and self management protocols.

\section{Dovepress}

This journal is indexed on PubMed Central, MedLine and CAS. The manuscript management system is completely online and includes a very quick and fair peer-review system, which is all easy to use. Visit $\mathrm{http}: / /$ www.dovepress.com/testimonials.php to read real quotes from published authors. 